\title{
Alcohol consumption and gender in rural Samoa
}

This article was published in the following Dove Press journal:

Substance Abuse and Rehabilitation

9 November 2010

Number of times this article has been viewed

\author{
Shawn S Barnes ${ }^{1,4}$ \\ Christian R Small2,4 \\ Tui Agaapapalagi Lauilefue' \\ Jillian Bennett ${ }^{3}$ \\ Seiji Yamada' \\ 'University of Hawaii John A Burns \\ School of Medicine, Honolulu, HI, \\ USA; ${ }^{2}$ University of California San \\ Diego, San Diego, CA, USA; ${ }^{3}$ Hawaii \\ Pacific University, Honolulu, HI, USA; \\ ${ }^{4}$ Outbound Eye Health International, \\ Honolulu, HI, USA
}

Correspondence: Shawn S Barnes 3414 Hardesty St. \#C, Honolulu, HI 968I6, USA

Tel +l 8082235966

Email barn2243@yahoo.com
Introduction and aims: There are significant gender differences in alcohol consumption throughout the world. Here we report the results of an alcohol consumption survey on the rural island of Savaii, in the Pacific nation of Samoa.

Design and methods: Eleven villages were selected for sampling using a randomized stratified cluster sampling methodology. A total of 1049 inhabitants over the age of 40 years (485 males and 564 females) were surveyed about alcohol consumption over the past year, and a $72.2 \%$ participation rate was achieved.

Results: A significant gender difference in alcohol consumption was found: $97.3 \%$ of women and $59.4 \%$ of men reported no alcohol consumption over the past year. This is one of the most significant gender differences in alcohol consumption in the world. No significant difference between genders was seen in those who consume only $1-5$ alcoholic drinks per week $(P=0.8454)$. However, significantly more males than females consumed 6-25 drinks per week $(P<0.0001)$, 26-75 drinks per week $(P<0.0001)$, and 75+ drinks per week $(P<0.0001)$.

Discussion and conclusion: This extreme gender difference in alcohol consumption is attributed to several factors, both general (alcoholic metabolism rates, risk-taking behaviors, general cultural taboos, etc) and specific to Samoa (church influence, financial disempowerment, and Samoan gender roles).

Keywords: Pacific, Samoa, gender, alcohol, behavior

\section{Introduction}

Alcohol-related morbidity and mortality account for a greater global health burden than tobacco products. ${ }^{1}$ It has been consistently shown through epidemiological studies that men tend to drink more, and more regularly, than women worldwide. ${ }^{2}$ Several reasons have been given for this near universal trait. Possible biological explanations for the alcohol consumption gender gap include evidence of a lower rate of the gastric metabolism of alcohol in females, ${ }^{3}$ smaller volumes of body water in which alcohol is distributed in females, ${ }^{4}$ and a higher likelihood of women experiencing hangover symptoms. ${ }^{5}$ Cultural explanations include a perception of drinking as a demonstration of masculinity and strength, social sanctions, or stigmas against alcohol consumption by women, higher levels of impulsivity and risk-taking in men, beliefs about the association between drinking and female promiscuity, and a tendency for men to use alcohol as a coping mechanism while women tend to use communication for that purpose. ${ }^{6}$

Alcohol consumption rates among women are on the rise worldwide, especially in Australia. ${ }^{7}$ It is hypothesized that as women achieve more in terms of education, social status, and economic independence, cultural restraints on alcohol consumption submit your manuscript $\mid$ www.dovepress.com

Dovepress

DOI: $10.2147 /$ SAR.SI 4755
Substance Abuse and Rehabilitation 2010:1 I-4

(C) 2010 Barnes et al, publisher and licensee Dove Medical Press Ltd. This is an Open Access article which permits unrestricted noncommercial use, provided the original work is properly cited. 
decrease, and there is a convergence of male and female drinking patterns. ${ }^{8}$

While evidence of a genetic propensity to alcoholism in Polynesians has been reported, ${ }^{9}$ comparatively few studies have investigated the epidemiology of alcohol consumption in Pacific populations. This lack of data is compounded by the inappropriate inclusion of Pacific populations with disparate populations of greater numbers. For example, in the United States, epidemiological data are often collected under the group "Asian and Pacific Islander". ${ }^{10}$ Such "lumping" of groups with significantly different cultures and ethnicities obscures the higher rates of alcohol consumption among Pacific Islanders, as their numbers are much lower than Asians in the United States, yet their alcohol consumption tends to be higher. ${ }^{11}$

Some notable studies have helped fill in the gaps of knowledge in Pacific alcohol consumption. Using alcohol sales and production figures rather than epidemiological surveys, McDonald and colleagues concluded that the per capita consumption of alcohol in Pacific nations such as Fiji, Samoa, and Tonga was significantly less than in nearby Australia and New Zealand. However, while a higher percentage of people in the Pacific abstain from alcohol, those who do not abstain tend to consume more, on average, than their counterparts in Australia or New Zealand. ${ }^{12}$ This pattern was also found in Pacific populations living in New Zealand. ${ }^{13}$

The independent nation of Samoa, formerly known as Western Samoa, is a relatively underdeveloped Pacific island nation located approximately halfway between Hawaii and New Zealand (Figure 1). Samoa's economy is primarily agricultural, with approximately $85 \%$ of all adults working solely in local subsistence farming and fishing. The total population in 2001 was approximately 175,000, ${ }^{14}$ divided between two main islands, Upolu and Savaii. The island of Upolu boasts the majority of the nation's population $(-135,000)$, as well as the capital city and a more modern lifestyle and economy, as residents of the expanding urban villages gain wage-based employment. While only $20 \mathrm{~km}$ of ocean separate Savaii from Upolu, the island of Savaii is much less populated $(\sim 2,000)$ and is among the least modernized regions of Polynesia with an economy almost entirely based on traditional Samoan agriculture and reef fishing, although a nascent tourist trade has been recently established. On Savaii, a traditional village form of government, based on a council of chiefs and local rule, is firmly in place. ${ }^{15}$

Alcohol was first introduced to Samoa in the 19th century by European whalers and beachcombers. For many decades consumption was kept rather modest due to missionary efforts

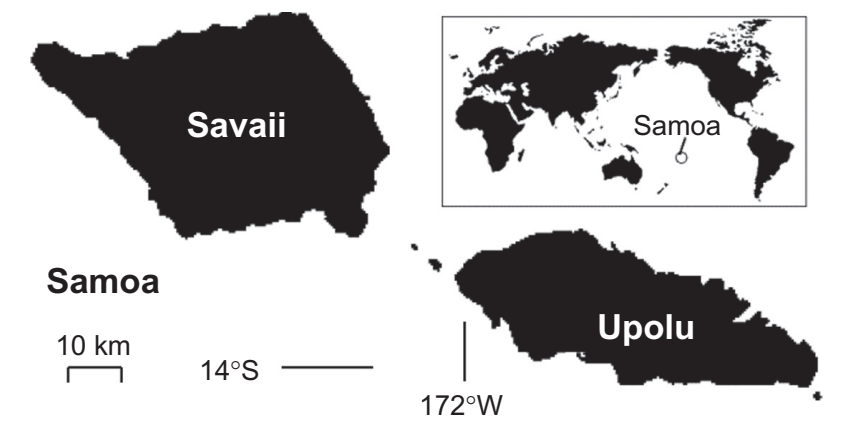

Figure I The independent nation of Samoa, South Pacific.

and lack of supply. A major increase in alcohol consumption came in the 1940s with the influx of over 10,000 American soldiers on Upolu. In the 1970s, Western Samoa Breweries was established, supplying the nation with its first and only nationally brewed beer, Vailima, whose slogan printed on every bottle is "Samoa's very own beer". ${ }^{16}$

\section{Methods}

In July 2009, a team of medical students, eye care professionals, and American Peace Corps volunteers provided eye exams and vision screenings for 1049 people in 11 villages on the rural island of Savaii, Samoa (population 42,000), using a randomized stratified cluster sampling methodology when choosing villages. All villagers 40 years of age or older were invited to participate, and a $72.2 \%$ participation rate was achieved across 11 villages. In addition to eye exams, demographic data were collected via questionnaire in the Samoan language, including the questions "Have you had any alcoholic drink in the last year?" and "How many drinks do you usually have in a week". Standard drinks were explained to participants to be any drink containing $14 \mathrm{~g}$ of pure alcohol $(355 \mathrm{~mL}$ of beer, $150 \mathrm{~mL}$ of wine, $45 \mathrm{~mL}$ of hard liquor).

This study was approved by the institutional review boards of the University of Hawaii and the Samoan Ministry of Health. Informed consent was obtained from all participants, and the guidelines of the Declaration of Helsinki were adhered to. All data collected were nonidentifiable.

\section{Results}

Results of the Savaii alcohol consumption survey are shown in Table 1. Of 564 females surveyed, 549 reported abstaining from all alcohol in the past year (97.3\%), while 288 out of 485 males (59.4\%) reported abstaining from all alcohol in the past year. The mean age of abstaining females (56.7 years) was significantly older, by Student's $t$-test, than nonabstaining females (50.8 years) $(P=0.038)$. The mean age of abstaining 
Table I Number of standard alcoholic drinks per week in males and females in Savaii, Samoa

\begin{tabular}{lllllll}
\hline & $\mathbf{N}$ & $\mathbf{0}$ (abstain) & $\mathbf{I - 5}$ & $\mathbf{6 - 2 5}$ & $\mathbf{2 6 - 7 5}$ & $\mathbf{7 5 +}$ \\
\hline Males & $485(46.2 \%)$ & $288(59.4 \%)$ & $4(0.8 \%)$ & $116(23.9 \%)$ & $56(\mathrm{II} .6 \%)$ & $21(4.3 \%)$ \\
Females & $564(53.8 \%)$ & $549(97.3 \%)$ & $3(0.5 \%)$ & $10(1.8 \%)$ & $3(0.5 \%)$ & 0 \\
Both sexes & 1049 & $837(79.8 \%)$ & $7(0.7 \%)$ & $126(12.0 \%)$ & $59(5.6 \%)$ & $21(0.2 \%)$ \\
\hline
\end{tabular}

Notes: One standard drink is defined as any drink containing $14 \mathrm{~g}$ of pure alcohol $(355 \mathrm{~mL}$ of beer, $150 \mathrm{~mL}$ of wine, $45 \mathrm{~mL}$ of hard liquor)

males (61.3 years) was significantly older than nonabstaining males $(55.8$ years $)(P<0.0001)$.

No significant difference, by Student's $t$-test, between genders was seen in those who consume only 1-5 alcoholic drinks per week $(P=0.8454)$. However significantly more males than females consumed 6-25 drinks per week $(P<0.0001), 26-75$ drinks per week $(P<0.0001)$, and $75+$ drinks per week $(P<0.0001)$.

\section{Discussion}

The gender difference in alcohol consumption in rural Samoa is striking. While only $2.7 \%$ of women over 40 report consumption of alcohol in the past year, $40.6 \%$ of men report alcohol consumption. While some of the significantly low drinking rates in rural Samoan women may be ascribed to the older age of the sample population (over 40 years), these rates must also be considered in the context of the Pacific region, where female alcohol consumption rates are some of the lowest in the world (Table 2). Indeed, six of the top 10 nations for female alcohol abstinence in Table 2 are Pacific nations (Fiji, Samoa, Marshall Islands, Kiribati, Micronesia, and American Samoa). The rurality of the Pacific may play a significant role in this. Previous reports have suggested that alcohol consumption rates among Samoan women rise significantly from rural to urban Samoa ${ }^{17}$ and from Independent Samoa to American Samoa to Samoans living in Hawaii. ${ }^{18}$ Although these studies are limited by small sample sizes, they posit that the reported rise in women's drinking correlates to the increase in the cash economy and Western lifestyle available in the more urban settings of Hawaii and American Samoa. This is in keeping with Neve's ${ }^{8}$ hypothesis that as women achieve more in terms of education, social status, and economic independence, cultural restraints on alcohol consumption decrease and male/female alcohol consumption patterns converge.

In addition to the factors already discussed for a gender gap in alcohol consumption, we posit certain cultural factors that are specific for rural Samoa. In rural Samoa, women tend to be financially disempowered. Money received by women through commerce, employment, or remittance must often be given to the chief (matai) of the family (usually male). This arrangement strongly discourages alcohol purchase by women.

Table 2 Gender differences in alcohol consumption worldwide

\begin{tabular}{|c|c|c|c|c|c|c|}
\hline Nation & Female abstainers (\%) ${ }^{\mathrm{b}}$ & Male abstainers (\%) & $\mathbf{N}$ (both sexes) & Ages & Time period $^{\mathrm{d}}$ & Year \\
\hline Egypt & 100.0 & 99.0 & $4,47 \mid$ & $18+$ & last year & 2001 \\
\hline Fiji & 97.9 & 78.8 & 3,190 & $12+$ & unknown & 1993 \\
\hline Samoa $^{a}$ & 97.3 & 59.4 & 1,049 & $40+$ & last year & 2009 \\
\hline Malaysia & 96.5 & 83.1 & 6,003 & $18+$ & lifetime & 2003 \\
\hline Marshall Islands & 95.5 & 80.6 & 363 & $15+$ & last year & 2000 \\
\hline Kiribati & 92.9 & 51.4 & 2,788 & $20+$ & unknown & $198 \mid$ \\
\hline Micronesia & 90.9 & 45.1 & 1418 & $18+$ & last year & 2000 \\
\hline Thailand & 90.2 & 44.1 & 46,980 & $15+$ & unknown & 2001 \\
\hline American Samoa & 89.7 & 73.0 & 2070 & $25-64$ & last year & 2007 \\
\hline India & 89.3 & 67.1 & 5,119 & $18+$ & last year & 2001 \\
\hline China & 73.1 & 27.5 & 9,301 & $18+$ & last year & 2001 \\
\hline Philippines & 72.6 & 27.8 & 10,034 & $18+$ & lifetime & 2003 \\
\hline United States & 38.2 & 29.3 & 68,126 & $12+$ & last year & 2002 \\
\hline Russian Federation & 25.8 & 12.4 & 2,983 & I8+ & lifetime & 2003 \\
\hline Australia & 20.8 & 14.1 & 26,744 & $14+$ & last year & 2001 \\
\hline Japan & 19.7 & 7.4 & 2025 & $20-64$ & last year & 2001 \\
\hline United Kingdom & 14.0 & 9.0 & 8,580 & $16-74$ & last year & 2000 \\
\hline Germany & 5.9 & 4.3 & 7,907 & $20-64$ & last year & 2000 \\
\hline
\end{tabular}

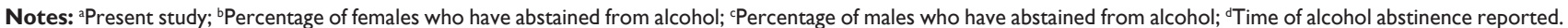
(all other data from World Health Organization') 
Within the Samoan cultural framework, there exist numerous women's groups whose purpose revolves mainly around their roles in the family, village, and church. Among other responsibilities, these groups ensure gathering places where women can come together and bond/discuss shared experiences in a male-free environment. Alcohol plays no role in these female gatherings. On the other hand, alcohol plays a major role in bringing the Samoan males together. Before European contact, Samoan men ingested kava, a traditional drink prepared from the root of the kava plant (Piper methysticum) found among many Polynesian cultures. Kava was ingested at traditional male gatherings, such as chiefly meetings, and has a mild analgesic effect, similar to that of alcohol. ${ }^{19}$ The traditional gender gap in kava consumption may help to drive the modern gender gap of alcohol consumption.

The traditional cultural landscape of Savaii, Samoa, offers a convenient baseline in which to investigate the social and cultural changes that come with Westernization. Here we offer a baseline for the rate of rural Samoan alcohol consumption as well as explanations, both general and specific to Samoa, of the role of gender in that rate. This information can be used to target alcohol awareness campaigns to those most at risk (males). Valuable future research towards this end would be to conduct a similar assessment of alcohol use in the semi-urban capital of Apia, Samoa. The adoption of a more Western lifestyle in Apia may suggest a different relationship between gender and alcohol.

\section{Disclosure}

The authors report no conflicts of interest in this work.

\section{Acknowledgments}

This work was supported by a grant from the Hawaii Ophthalmological Society and the John A Burns School of Medicine Maguire Fund. Hawaiian Airlines generously provided transportation. A special thanks is reserved for the people of Savaii for their alofa, onosai, and faaaloalo towards two utufiti palagi over many years.

\section{References}

1. World Health Organization. Global Status Report on Alcohol. New York, NY: World Health Organization; 2004.

2. Wilsnack RW, Wilsnack SC, Obot IS. Why study gender, alcohol, and culture? In: Obot IS, Room R (editors). Alcohol, Gender, and Drinking Problems. Geneva, Switzerland: World Health Organization; 2005.

3. Baraona E, Abittan CS, Dohmen K, et al. Gender differences in pharmacokinetics of alcohol. Alcohol Clin Exp Res. 2001;25:502-507.

4. Mirand AL, Welte JW. Total body water adjustment of mean alcohol intakes. J Subst Abuse. 1994;6:419-425.

5. Slutske WS, Piasecki TM, Hunt-Carter EE. Development and initial validation of the Hangover Symptoms Scale: prevalence and correlates of hangover symptoms in college students. Alcohol Clin Exp Res. 2003;27:1442-1450.

6. Nolen-Hoeksema S. Gender differences in risk factors and consequences for alcohol use and problems. Clin Psychol Rev. 2004;24:981-1010.

7. Roche AM, Deehan A. Women's alcohol consumption: emerging patterns, problems, and public health implications. Drug Alcohol Rev. 2002;21:169-178.

8. Neve RJM, Lemmens PH, Drop MJ. Gender differences in alcohol use and alcohol problems: mediation by social roles and gender-role attitudes. Subst Use Misuse. 1996;32:1439-1459.

9. Chambers GK, Marshall SJ, Robinson GM, Maguire S, NewtonHowes J, Chong NL. The genetics of alcoholism in Polynesians: alcohol and aldehyde dehydrogenase genotypes in young men. Alcohol Clin Exp Rev. 2002;26(7):949-955.

10. Bitton A, Zaslavsky AM, Ayanian JZ. Health risks, chronic diseases, and access to care among US Pacific Islanders. J Gen Intern Med. 2010;25(5):435-440.

11. Wong MM, Klingle RS, Price RK. Alcohol, tobacco, and other drug use among Asian American and Pacific Islander adolescents in California and Hawaii. Addict Behav. 2004;29:127-141.

12. McDonald D, Elvy G, Mielke J. Alcohol in the South Pacific: the mid-1990s. Drug Alcohol Rev. 1997;16:383-390.

13. Sundborn G, Metcalf PA, Gentles D, et al. From kava to lager: alcohol consumption and drinking patterns for older adults of Pacific ethnic groups and Europeans in the Diabetes Heart and Health Study (DHAHS) 2002-2003, Auckland New Zealand. Pac Health Dialog. 2009;15(1):47-54.

14. Statistical Services Division (2001) Census of Population and Housing 2001. Available from: http://www.spc.int/prism/Country/ws/stats/ census_survey/Census2001/popncensus_introdn_01.htm. Accessed $2010 \mathrm{Jul} 17$.

15. O'Meara T. Samoan Planters: Tradition and Economic Development in Polynesia. Fort Worth, TX: Holt, Rinehart and Winston; 1990.

16. Lima I. Alcohol in Samoa: A Social History. Christchurch, New Zealand: Macmillan Brown Centre for Pacific Studies; 2005.

17. Hodge AM, Dowse GK, Toelupe P, et al. The association of modernization with dyslipidaemia and changes in lipid levels in the Polynesian population of Western Samoa. Int J Epidemiol. 1997;26(2):297-306.

18. Hanna JM, Fitzgerald MH. Acculturation and symptoms: a comparative study of reported health symptoms in three Samoan communities. Soc Sci Med. 1993;36(9):1169-1180.

19. Mead M. The Social Organization of Manua. Honolulu, HI: Bishop Museum Press; 1969.
Substance Abuse and Rehabilitation

\section{Publish your work in this journal}

Substance Abuse and Rehabilitation is an international, peer-reviewed, open access journal publishing original research, case reports, editorials, reviews and commentaries on all areas of addiction and substance abuse and options for treatment and rehabilitation. The manuscript management system is completely online and includes a very quick and

\section{Dovepress}

fair peer-review system. Visit http://www.dovepress.com/testimonials. php to read real quotes from published authors. 